\title{
Turismo científico em paleontologia no município de Faxinal do Soturno - RS
}

Eliane Ferreira dos Santos

Átila Augusto Stock da Rosa

\section{RESUMO}

Este artigo fundamenta-se no levantamento das ocorrências fossilíferas no município de Faxinal do Soturno, a fim de incentivar o turismo científico. Nesta perspectiva, investiga-se a dinâmica da atividade turística e as estratégias utilizadas para seu desenvolvimento. Prioriza-se também o estudo do espaço geográfico, averiguando-se as características físicas, humanas e econômicas do município. Em função das características geológicas e paleontológicas existentes no município, propõe-se a implantação do turismo científico em paleontologia como meio de desenvolvimento econômico local, apresentando um roteiro turístico, no qual salienta-se a localização dos afloramentos indicados para visitação, a sua litologia e a potencialidade fossilífera, bem como a descrição do ambiente no passado. Por fim, sugere-se melhorias na infra-estrutura e nos serviços e equipamentos turísticos para que se desenvolva o turismo científico.

Parte do Trabalho de Graduação apresentado no Curso de Geografia (Bacharelado) - Universidade Federal de Santa Maria 
PALAVRAS CHAVES:Afloramentos fossilíferos; Triássico Superior; Répteis fósseis; Turismo científico em paleontologia.

\section{ABSTRACT}

This work is based on the survey of fossiliferous outcrops at the Faxinal do Soturno municipality, in order to stimulate the scientific tourism. From this point of view, the dynamics and strategies of the touristic activity were investigated, with a priority in the geographic space (physical, human and economical characters). Due to the geologic and paleontologic characteristics existent at the municipality, the settlement of scientific tourism in paleontology is proposed, as a way of local economic development. A tour route shows the localization of the proper outcrops, its lithology, fossiliferous potentiality, and description of the paleoenvironment. Finally, some infrastructure improvements are recommended.

KEY WORDS:Fossiliferous outcrops; Upper Triassic; Fossil reptiles; Scientific tourism in paleontology.

\section{INTRODUÇÃO}

O Turismo e a Ciência Geográfica estão intimamente interrelacionados, pois o efeito turístico realiza-se no âmbito geográfico, implicando deslocamento no espaço, além de buscar lugares históricos ou naturais. Por este motivo, tem-se a necessidade de conhecer as potencialidades do espaço geográfico, com o intuito de incentivar um tipo específico de turismo.

Este trabalho teve como propósito realizar um estudo sobre os afloramentos fossiliferos no município de Faxinal do Soturno (Figura 1), visando o desenvolvimento do turismo científico em paleontologia.

O município de Faxinal do Soturno está situado na região central do Rio Grande do Sul, limitado pelas coordenadas geográficas $29^{\circ} 29^{\prime} 00^{\prime \prime}$ e $29^{\circ} 37^{\prime} 00^{\prime \prime}$ de latitude sul e de $53^{\circ} 22^{\prime} 00^{\prime \prime}$ e $53^{\circ} 33^{\prime} 00^{\prime \prime}$ de longitude oeste, conforme as cartas topográficas de Camobi, Faxinal do Soturno e Nova Palma, da Diretoria do Serviço Geográfico, na Escala 1:50.000. O município abrange uma área de $180 \mathrm{~km}^{2}$ de extensão, limitando-se ao norte com o município de Nova Palma, a oeste com Ivorá e Silveira Martins, ao sul com São João do Polêsine e a leste com Dona Francisca (Figura 1). Estão inseridos no município faxinalense, além da sede municipal, as localidades: Sítio Alto, Sítio dos Melos, Linha Guarda Mor, Val Veronês, Saxônia 
e Santos Anjos, situadas na margem direita do rio Soturno; Linha Nova Palma, Linha São Luiz, Novo Treviso, Colonial, Linha Formosa e Linha Dona Francisca, localizadas na porção esquerda do rio Soturno.

\section{FUNDAMENTAÇÃO TEÓRICA}

A prática do turismo pode ter iniciado há milhares de anos, na antiga Grécia, entre os fenícios, ou na antiga Roma, dependendo da abordagem de cada autor, conforme as descobertas arqueológicas até o momento.

Ao longo dos anos, o turismo tem-se mantido em crescimento constante, sendo conceituado pela primeira vez no século XVII na Inglaterra, referindo-se a um tipo especial de viagem. Porém, o turismo que se conhece hoje ligado ao modo de produção e ao desenvolvimento tecnológico surgiu no século XIX, após o advento da Revolução Industrial. A partir de então, inicia-se as primeiras viagens organizadas com a intervenção de agências de viagens (SENAC, 1998 a).

A partir do momento em que começaram os estudos científicos do turismo, muitos conceitos têm sido dados para o turismo. A definição aceita pela Organização Mundial de Turismo (OMT) é, conforme FLORES (1974, apud PAGANI et al., 1996), a soma de relações e serviços resultantes de uma mudança voluntária para uma residência temporária, não motivada por razões de negócios ou profissionais.

Nos tempos atuais, à medida que a tecnologia avança, a vida nas cidades se torna mais difícil pela presença cada vez mais acentuada da poluição visual, sonora e do ar, além do crescente fluxo de pessoas e veículos, tornando a vida da população urbana agitada.

Para desvincular-se desse ambiente conturbado é crescente o número de pessoas que buscam áreas onde haja ar puro, silêncio e um reencontro com a natureza.

Entretanto, há pessoas que almejam nas férias apreciar a arquitetura de um lugar, conhecer a cultura, os costumes e hábitos de um povo, inserir-se nas multidões, participar de festas, eventos e visitações, tudo isto contrastando com a tranqüilidade da vida doméstica e a rotina em que estão habituados.

Assim, surge a "indústria" do lazer e do turismo como forma de livrar-se do cotidiano constrangedor. A utilização deste termo para o turismo, segundo alguns autores, deve-se à existência 
de serviços e elementos que possibilitem e facilitem os deslocamentos das pessoas, assim como o uso dos recursos naturais sem esgotá-los, inserindo-o no setor terciário ou de serviços.

O turismo se tornou, hoje, um fenômeno social e um fator de desenvolvimento econômico nas áreas receptoras capaz de mudar níveis de vida e estruturas sócio-econômicas com o surgimento de novas atividades profissionais, distribuição dos rendimentos e obtenção de receitas para as economias públicas, na forma de taxas, impostos e contribuições (SENAC, 1998 b).

Num mundo globalizado, intensos fluxos humanos convergem para os mais variados locais do planeta. Estes movimentos são verificados tanto na zona urbana quanto na zona rural, e em regiões com recursos naturais como praias, lagos, florestas, desertos, montanhas, parques botânicos e zoológicos, sítios históricos e outros. O deslocamento é feito no mesmo país ou em outro, desde que tenha atrações importantes e explorado pela "indústria" turística e seus agentes (CAVACO, 1996).

Entretanto, em alguns casos, geralmente onde praticase o turismo internacional dito massificado, o desenvolvimento turístico não traz benefício para a população receptora, pois resulta em efeitos de dependência e exploração econômica e política, bem como degradação cultural, moral e ambiental nas áreas acolhedoras. Este fato ocorre em virtude da implantação de megaprojetos de empresas de capitais transnacionais que dominam hegemonicamente o mercado mundial, captando divisas, porém, a um alto custo às populações locais e para o meio ambiente, pois mesmo em áreas inadequadas ao turismo, é montada uma infra-estrutura com o emprego de alta tecnologia e, com isso, descaracterizando a identidade do lugar (RODRIGUES, 1996).

Punta del Leste, balneário no Uruguai, em Viña del Mar, no Chile, e em Las Leñas, estação de esqui na Argentina, são exemplos de áreas que aplicam o turismo internacional de massa e o turismo sazonal, segundo RODRIGUES (1996: 28). Tais áreas dependem das condições climáticas para gerarem recursos econômicos. Em épocas de baixa estação, as atividades econômicas ficam praticamente estagnadas, ocorrendo fluxos sazonais de turistas, comprometendo a força de trabalho empregada no turismo, sendo forçada a deslocar-se no território em busca de emprego, aceitando baixos salários em outros setores da atividade. Por isso, o turismo deve ser encarado como mais uma forma de contribuição para o desenvolvimento econômico da região e não única fonte de renda para o local. 
Por essas razões, propõe-se o turismo alternativo como forma de amenizar os danos causados pelo turismo convencional, tanto na natureza quanto no modo de vida da população.

\begin{abstract}
"Turismo alternativo, ecoturismo, turismo verde, turismo leve, turismo responsável, turismo rural? Em qualquer caso, formas de turismo que em princípio respeitam as capacidades de carga dos meios de acolhimento, em termos naturais, culturais e sociais, com conservação dos recursos locais, físicos e humanos, incluindo os de interesse turístico, diminuindo custos e elevando benefícios e, não menos importante, reduzindo a saida de divisas ..." (CAVACO, 1996: 105).
\end{abstract}

Turismo em áreas naturais é um segmento do setor turístico, no qual se desenvolvem atividades no espaço natural, com interações entre o homem e a natureza, resultando benefícios nos planos sociais, econômicos e ecológicos.

O turismo ecológico, uma das formas do turismo alternativo, difere do turismo tradicional, devido a participação de um número reduzido de pessoas e, consequentemente, exigindo um pequeno porte de equipamentos, no que se refere a hospedagem e aos meios de transporte.

O turismo ecológico é desenvolvido de maneira conservacionista, procurando conciliar a exploração turística com o meio ambiente, bem como proporcionar aos turistas contato com os recursos naturais e culturais da região, almejando a formação de uma consciência ecológica, através da interpretação do ambiente, a fim de promover o bem-estar das populações envolvidas.

O ecoturismo é um tipo de atividade turística que envolve várias modalidades, tais como: trekking (caminhadas longas), hiking (caminhadas curtas), observação da flora e fauna, montanhismo, turismo aquático, turismo espeleológico e turismo científico (SENAC, 1998 d).

As necessidades locais, a potencialização dos seus recursos naturais e humanos e a valorização das diferenças representadas pelo lugar, somente serão respeitadas mediante a intervenção do poder público e da empresa privada, participação da sociedade civil através da atuação das organizações não governamentais (ONG'S) e das associações de base, assim como o envolvimento das Universidades, nos seus programas de pesquisa e extensão (RODRIGUES, 1996). 
O potencial de cada região é que determina o tipo específico de turismo a ser explorado. A geografia assume papel importante como elemento de identificação e caracterização do espaço geográfico, uma vez que a prática do turismo realiza-se neste âmbito.

Na área de turismo, o processo de desenvolvimento está estreitamente vinculado à pesquisa e ao ensino. A pesquisa funciona basicamente como "mola propulsora" do sistema técnico-científico, estabelecendo um fluxo contínuo de conhecimento (REJOWSKI, 1996).

As instituições de ensino e pesquisa precisam ser consultadas, e as populações receptoras devem participar do processo, visto que a cientificidade e os recursos naturais constituem parte integrante do fenômeno turístico. Dessa forma, o turismo se autosustentará por mais de algumas décadas, além de gerar divisas (CORIOLANO, 1996).

Turismo científico consiste em programas específicos para aprendizado, treinamento ou pesquisa "in loco", envolvendo instituição de ensino, pesquisa e extensão e organizações não governamentais (SENAC, $1998 \mathrm{c}$ ).

Segundo BENI (1998: 278), o turismo científico desenvolve-se em áreas que, por motivos científicos, representam importantes testemunhos da cultura humana (da pré-história à época atual) e servem para pesquisas arqueológicas e/ou paleontológicas. Estas áreas são denominadas sítios arqueológicos e paleontológicos, locais evocativos de acontecimentos cívicos, históricos, lendários ou pré-históricos, que permitam a realização de pesquisas e visitação pública.

O turismo em paleontologia está inserido no turismo científico, uma vez que os espaços constituídos de fósseis vegetais e animais requerem estudos e pesquisas, a fim de serem valorizados e preservados.

A investigação científica proporciona o reconhecimento e a compreensão do fenômeno natural, no caso o patrimônio fossilífero. As pesquisas concluídas geram informações que, veiculadas através dos meios de comunicação, incentivam novas pesquisas.

De acordo com REJOWSKI (1996: 13), este ciclo torna-se contínuo e propicia a introdução de novos conhecimentos, refutando ou não os já existentes; ou a confirmação e consolidação do conhecimento já existente, ampliando a sua área de aplicação.

Para facilitar os estudos e pesquisas, assim como a conservação dos recursos naturais, foram criadas, no Brasil, Unida- 
des de Conservação com a finalidade de preservar a biodiversidade natural, os recursos hídricos, os solos, as paisagens cênicas, os sítios arqueológicos e paleontológicos e o patrimônio cultural e natural. Além disso, favorecem a pesquisa científica, o manejo e o monitoramento ambiental formal ou informal e possibilitam recreação ao ar livre.

\begin{abstract}
"Unidades de Conservação (UCS) são porções do território, incluindo águas territoriais, com características naturais de relevante valor, de domínio público ...., com objetivos e limites definidos, sob regimes especiais de administração e às quais aplicam-se garantias de proteção." (FUNATURA, 1989, apud SAA-RS, 1994)
\end{abstract}

Há diferentes tipos de Unidades de Conservação, dependendo dos objetivos prioritários de cada área. Um tipo consiste nos parques Nacionais, Estaduais e Municipais.

Segundo o Macrozoneamento Agroecológico e Econômico do Estado do Rio Grande do Sul (SAA-RS, 1994), parque tem como principal objetivo:

“... a preservação integral do ambiente natural, conciliando este objetivo com os de pesquisa, monitoramento, educação ambiental e recreação. Só permite o uso indireto dos recursos. Deve incluir beleza cênica. É de domínio público."

As Unidades de Conservação devem possuir facilidades de acesso e infra-estrutura adequada, a fim de proporcionar aos visitantes a interpretação dos fenômenos da natureza, bem como a conscientização no que tange à preservação dos recursos naturais, culturais e históricos.

As trilhas interpretativas da natureza representam importante instrumento de apoio para esse tipo de atividade.

Conforme DUTRA \& HERCULIANI (1990, apud PAGANI et al., 1996: 152), um sistema de trilhas é formado por um conjunto de caminhos e percursos construídos com diversas funções, desde a vigilância até o turismo.

Os métodos de interpretação de trilhas são, de acordo com HYPKI \& LOOMIS JUNIOR (1981, apud SILVA, 1996: 162-163) caminhadas dirigidas, utilizando um intérprete como guia; caminhadas autodirigidas, constituídas por rótulos numerados ao longo do percurso da trilha, a qual os visitantes adquirem um folheto explicativo com numeração correspondente; caminhadas autodirigidas com pla- 
cas e painéis interpretativos, estes geralmente feitos de madeira que tenham letras ou entalhes onde as mensagens devem ser curtas e com pequenas ilustrações.

Outra forma de os visitantes interpretarem o meio ambiente é através de centros de informações a turistas. Estes centros encontram-se em salas ou prédios especiais nos quais podem ser expostas informações minuciosas a respeito do recurso natural a ser visitado. As exposições podem incluir fotografias, painéis com texto explicativo, mapas, folders, além disso, podem estar disponíveis para venda livros e guias pormenorizados (MCINTYRE, 1994).

Os centros de educação, situados em prédios específicos ou em espaços reservados juntamente com os centros de informações, podem oferecer atividades ou exposições mais educativas. Tratam-se de salas que permitam dar aulas, palestras ou sessões de discussão, com equipamentos audiovisuais para mostrar filmes ou produções em vídeo.

Assim, para oferecer aos turistas toda essa infra-estrutura é indispensável o planejamento de um roteiro turístico. Mas, para isto é necessário conhecer a caracterização do espaço, bem como a potencialização dos recursos naturais, os quais serão abordados a seguir.

\section{MATERIAL E MÉTODO}

Para a realização do trabalho buscou-se informações a partir de um referencial bibliográfico do assunto em questão. Os estudos foram complementados com análise de cartas topográficas e trabalho de campo. Após interpretação dos conhecimentos adquiridos no trabalho de campo, elaborou-se um roteiro turístico, indicando através de pontos numerados os afloramentos sugestivos para visitação e estudos.

\section{CARACTERIZAÇÃO DA ÁREA DE ESTUDO E POTENCIAIS TURÍSTICOS INTERESSE PALEONTOLÓGICO}

Geomorfologicamente, o município está situado na zona de transição entre o Planalto Meridional Brasileiro, subdividido entre topo e rebordo do Planalto, formado por rochas vulcânicas e sedimentares da Formação Serra Geral, e a Depressão Central ou Periférica, subdividida em coxilhas e planícies aluviais, constituída 
por rochas sedimentares da Bacia do Paraná (MAPA GEOLÓGICO DO ESTADO DO RGS, 1974).

Do ponto de vista geológico, o município faz parte da seqüência sedimentar Gondwânica que preencheu a Bacia do Paraná, com arenitos, argilitos e siltitos de diferentes formações geológicas durante os Períodos Triássico, Jurássico e Cretáceo, bem como sucessivos derrames de lavas, resultantes do vulcanismo fissural que recobriu os sedimentos da Bacia do Paraná no Cretáceo.

A geologia na área é constituída por unidades litoestratigráficas representadas da base para o topo pela Formação Santa Maria - Membro Alemoa, de idade Triássico Médio Superior, Formação Caturrita, do Triássico Superior, pertencentes ao Grupo Rosário do Sul; Formações Botucatu e Serra Geral, datando do Período Cretáceo do Grupo São Bento.

Paleontologicamente, o município apresenta 33 afloramentos de rocha identificados como fossilíferos, potencialmente fossilíferos e afossilíferos até o momento, em função dos achados históricos ou realizados durante os trabalhos de campo.

\section{INTERESSE SÓCIO-CULTURAL}

O município de Faxinal do Soturno possui 7.194 habitantes, sendo que 3.943 residentes na zona urbana e 3.251 na zona rural, correspondendo a um índice aproximado de $54,8 \%$ e $45,1 \%$, respectivamente, do efetivo total. A densidade demográfica é de 43,36 $\mathrm{hab} / \mathrm{km}^{2}$, conforme os dados da Fundação de Economia e Estatística (FEE, 1995). A economia do município baseia-se no setor primário, prevalecendo a agricultura diversificada, com destaque para 0 cultivo do arroz (FEE, 1995).

A maioria da população faxinalense é descendente de italianos, revelando o traço cultural típico existente no município, em especial na tradição, hábitos e costumes dos moradores, expressas na gastronomia, arquitetura, festas, danças, cantos e religiosidade.

O município exibe uma arquitetura antiga que revela o predomínio da cultura italiana, explícita em edificações mistas de pedra e madeira, como por exemplo: o Moinho Antoniazzi, fundado em 1950 por Vitélio Antoniazzi, na localidade de Novo Treviso; o sobrado da família Maraschin, construído em 1888 e reformado em 1915, na localidade de Linha Guarda-Mor e o sobrado da família Montagner, situado próximo à sede municipal. Tais edificações podem ser aproveitadas para possíveis visitações ou até mesmo servirem de pousada para os turistas, desde que restauradas, pois reve- 
lam o dia-a-dia dos imigrantes.

A presença da cultura italiana é marcante no calendário de eventos e festas típicas religiosas. Os eventos que se destacam são: o Torneio Interseleções de Futebol (março), Festival do Vinho e do Queijo e Feira Colonial (junho), Semana Farroupilha (setembro), Semana do Município (novembro), a Exposição Feira Agroindustrial e Comercial - EXPOFAX (dezembro); e Natal Som e Luz (dezembro).

Nos últimos anos, o município tem recebido muitos visitantes, em função das festas religiosas que são realizadas nas paróquias e santuários, onde se tem verificado um acréscimo do turismo religioso (CORADINI, 1997). Este fato é crucial, visto que a atividade turística necessita da agregação de diferentes formas de turismo.

Na localidade de Sítio Alto, encontra-se a Gruta Nossa Senhora de Lourdes. Trata-se de um símbolo religioso, o qual é reverenciado a cada ano no mês de fevereiro, onde os fiéis fazem suas orações e devotos, além de apreciarem a beleza natural do lugar. A imagem situa-se numa gruta natural em meio a uma vegetação arbórea.

O Santuário Mãe e Rainha Três Vezes Admirável de Schoenstatt, situado no centro da sede municipal, é visitado por pessoas que buscam a oração, paz e tranqüilidade.

A cultura italiana também é expressa na gastronomia, destacando-se os seguintes restaurantes: Moby Dick, os restaurantes do Hotel Zanon e do Hotel Havaí, Esporte Clube Cruzeiro, Meu Cantinho e a Lancheria da Gema. Dentre estes, os hotéis Zanon e Havaí oferecem aos visitantes as suas dependências para hospedagem.

\section{PROPOSIÇÃO DE UM ROTEIRO DE TURISMO CIENTÍFICO NO MUNICÍPIO DE FAXINAL DO SOTURNO - RS}

O conjunto de atrativos culturais e naturais de uma região é o que determina o tipo específico de turismo a ser desenvolvido. No caso da área em estudo, optou-se pelo turismo científico, que em função de suas características geológicas e paleontológicas oferece possibilidades de estudos e pesquisas mais detalhadas realizadas pelas instituições de ensino. Dessa forma, contribui-se para o 
enriquecimento cultural do turista interessado em conhecer estes depósitos fossilíferos.

A exploração, neste sentido, estimula a conscientização do turista e da população local, no que se refere à atração e conservação do patrimônio fossilífero. No entanto, é imprescindível o planejamento de um roteiro turístico, a fim de proporcionar aos visitantes a possibilidade de visualizarem as formações geológicas que afloram na superfície terrestre e o conhecimento sobre as ocorrências fossilíferas, através de um entendimento lógico das modificações ambientais no passado, bem como suas conseqüências para a vida. Além disso, contribui para a realização de novos estudos e escavações, visando a perspectiva de outras descobertas fossiliferas.

Os afloramentos identificados como potenciais para a prática do turismo científico, estão inseridos no roteiro sobreposto no mapa do município, constituindo-se o itinerário possível de ser visitado pelos turistas e estudiosos (Figura 1). Estabeleceu-se pontos numerados para os afloramentos, correspondendo a uma seqüência facilitada pelas vias de acesso. O percurso do roteiro pode ser feito por veículos comuns, pois na maioria dos casos, os afloramentos estão situados à margem das estradas. Porém, é aconselhável para melhor observação das formações geológicas e dos possíveis materiais fossilizados, uma caminhada entre os afloramentos mais próximos.

O roteiro proposto parte da cidade de Faxinal do Soturno em direção ao município de Nova Palma, no sentido sul-norte, a qual encontra-se os pontos 1, 2 e 3 à margem leste da estrada RS 149. Retornando pela mesma rodovia, antes de chegar à sede municipal, há um trevo de acesso para uma estrada secundária a norte, não pavimentada, que leva à localidade de Linha São Luiz, onde são verificados os pontos 4,5 e 6 . Mais adiante, há um entroncamento que, direcionando-se à leste, dá acesso à localidade de Novo Treviso, onde está o ponto 7. $\mathrm{Na}$ estrada que liga Novo Treviso até Colonial, observa-se os pontos $8,9,10$ e 11 .

De Faxinal do Soturno segue-se às localidades de Santos Anjos, Sítio dos Melos até Sítio Alto, onde se encontra o ponto 12. No sentido norte-sul, na via que interliga Sítio Alto a Linha Guarda-Mor, verifica-se o ponto 13. Retorna-se a Santos Anjos e Faxinal do Soturno, a qual percorrendo a RS 348 chega-se ao ponto 14 , sendo este a finalização do roteiro. 


\section{PONTOS DO ROTEIRO}

\section{Ponto 1: Formação Santa Maria - Membro Alemoa}

Esta formação limita-se a uma pequena porção ao norte do município, especificamente, a leste da via RS 149, no km 149.

$O$ afloramento constitui-se de arenitos, siltitos e argilitos de coloração avermelhada da Formação Santa Maria, Membro Alemoa, contrastando com os arenitos arroxeados da Formação Caturrita, verificando-se assim o contato entre ambas formações.

Este afloramento data do Período Triássico Médio Superior, em torno de 230 milhões de anos. Afossilífero até o momento, porém importante pelo fato da Formação Santa Maria representar uma fonte comum de fósseis animais e vegetais. Neste afloramento, a Formação Santa Maria foi depositada em um rio meandrante, em que os animais viviam às margens dos canais, alimentando-se da vegetação rasteira. Eventualmente, alguns destes répteis morriam e seus corpos jaziam nas planícies de inundação, ou eram levados para dentro do rio pelas enxurradas. Com a preservação por soterramento, hoje tem-se uma coleção imensa de tetrápodes fósseis nestas rochas.

\section{Ponto 2: Formação Serra Geral}

Afloram rochas basálticas a leste da estrada RS 149, a $7 \mathrm{~km}$ da sede municipal. Caracteriza-se por apresentar um registro quase completo do perfil de um derrame, uma porção vítrea, uma de aspecto maciço e outra de basalto vesicular com bolhas de ar elípticas vazias.

Afloramento afossilífero, mas local apropriado à visitação e pesquisas por pertencer a Formação Serra Geral. Este afloramento possibilita a visualização das rochas basálticas, as quais são extraídas para serem usadas na indústria ornamental e na indústria da construção civil, sendo de significativo valor econômico.

No passado, quando o Pangéia iniciou sua separação, a crosta terrestre sofreu profundas fissuras por onde extravasou lavas basálticas provindas do manto. A ruptura fez com que o magma diminuísse sua pressão e viscosidade, facilitando a expansão dos gases que se encontravam dissolvidos no magma, formando bolhas.

No momento em que o magma entrou em contato com a superfície, consolidou-se formando o basalto, cobrindo toda a Bacia do Paraná, no Período Cretáceo, preservando assim as formações anteriores. 


\section{Ponto 3: Formação Caturrita}

Este ponto situa-se no corte a leste da rodovia RS 149. Expõe-se, no topo e na base, arenitos finos a médios, de cor rósea e composição quartzosa, que se intercalam com camadas de siltitos de cor avermelhada.

A Formação Caturrita data do Período Triássico Superior. Neste período, todas as terras estavam reunidas em um só continente, chamado Pangéia. A região estudada fazia parte de uma grande área de deposição chamada Bacia do Paraná, e aqui corriam rios entrelaçados sobre uma extensa planície.

Os rios entrelaçados apresentam canais largos, não variando a direção da correnteza, pouca cobertura vegetal, solo impermeável e declividade acentuada, ocasionando forte escoamento superficial e rápido transporte dos sedimentos durante o regime de enxurradas, predominando depósitos de areia.

\section{Ponto 4: Formação Caturrita}

Ponto situado a leste da via de acesso Faxinal do Soturno-Linha São Luiz, a 1,2 km da sede municipal. Trata-se de uma área escavada que fez aflorar camadas distintas de arenitos e siltitos da Formação Caturrita.

No nível basal expõe-se uma camada de arenito fino, maciço, de coloração alaranjada, com 3 metros de espessura, apresentando estratificação plano-paralela. Na base deste nível há intraclastos pelíticos, que são clastos retrabalhados pela sedimentação da bacia.

No nível médio, há argilito e siltito amarronado, intercalados por camadas milimétricas a centimétricas de arenito fino com marcas de ondas preservadas em níveis de óxido ferro (Limonita).

A camada superior apresenta intercalações centimétricas a métricas de arenito fino e pelito de cor marromavermelhada. Estratificação cruzada cavalgante com paleocorrente direcionada para o sul. Presença de diques clásticos e bioturbações verticais com cerca de $3 \mathrm{~mm}$ de espessura. Há também uma camada de $30 \mathrm{~cm}$, aproximadamente, de arenito fino a médio com estratificação cruzada acanalada, indicando a direção da paleocorrente para sudoeste. Neste tipo de estratificação os estratos acham-se inclinados em relação ao plano horizontal, resultantes dos transportes de detritos arenosos de carga de fundo. Cada seqüência consiste em estrutura de escavação por erosão preenchida por sedimentos com lâminas recurvadas, indo das bordas para o eixo do canal e de 
montante para jusante da paleocorrente. Assim, tem-se uma idéia perfeita do sentido da corrente destes rios antigos.

No topo do nível superior predominam os pelitos.

A Formação Caturrita data do Período Triássico Superior revelando um ambiente fluvial com predomínio de areia.

O local é favorável à visitação e as pesquisas paleontológicas, pois trata-se de um afloramento fossilífero, do qual foram coletados fragmentos de mamíferos primitivos por pesquisadores da Fundação Zoobotânica do Estado do Rio Grande do Sul.

\section{Ponto 5: Formação Botucatu}

Localiza-se a $4,5 \mathrm{~km}$ da sede municipal, à margem leste da estrada, próximo à localidade de Linha São Luiz, em propriedade privada.

O afloramento encontra-se numa área arborizada com cotas altimétricas em torno de 180 metros, na qual afloram arenitos finos de cor esbranquiçada da Formação Botucatu, com estratificação cruzada de grande porte. Este tipo de estratificação indica que houve a migração de dunas eólicas.

A predominância de arenitos bimodais finos a médios igualmente revela que houve depósito de origem eólica, pois o vento, em geral, tem a capacidade de transportar apenas sedimentos de granulometria menor.

A Formação Botucatu data do início do Período Cretáceo quando a região fazia parte de um grande deserto de clima quente e árido, que abrangia toda a região da Bacia do Paraná, em que foram depositados sedimentos eólicos. Há aproximadamente 130 milhões de anos, a crosta terrestre se rompeu e deixou fluir derrames de lavas basálticas, preservando as dunas eólicas do deserto de Botucatu.

A área é indicada para uma caminhada em meio à vegetação, pois permite além da observação da formação geológica, o contato com a natureza, oferecendo descanso, tranqüilidade e ar puro ao visitante.

\section{Ponto 6: Formação Botucatu e Formação Serra Geral}

Localizado à margem oeste da estrada que liga Faxinal do Soturno à Linha São Luiz, a $5,8 \mathrm{~km}$ da sede, aflora o contato entre arenitos da Formação Botucatu e basaltos da Formação Serra Geral, representado por uma cascata.

O contato entre ambas formações revela que no Perío- 
do Cretáceo, a crosta terrestre rompeu-se, ocasionando a separação do Pangéia. Derrames de lavas basálticas extravasaram pelas fissuras, cobrindo o deserto de Botucatu.

\section{Ponto 7: Formação Caturrita}

A uma distância de $9 \mathrm{~km}$ da sede municipal, situado na localidade de Novo Treviso, afloram arenitos maciços de cor variada indo do alaranjado ao rosa, com ausência de argila e possuindo intraclastos pelíticos da Formação Caturrita datando do Período Triássico Superior. Esta litologia torna-se interessante pelo fato de apresentar estruturas circulares de diâmetros variados, mimetizando pegadas de animais.

$\mathrm{Na}$ localidade também se encontra o museu histórico municipal, servindo de depósito de peças utilizadas pelos grupos indígenas, louças, vestimentas, adornos e utensílios de trabalho dos colonizadores italianos, bem como alguns materiais fósseis. A visitação desperta a preservação e a valorização do patrimônio histórico, cultural e natural.

Após a visitação ao museu sugere-se um breve passeio pela localidade, a fim de admirar a arquitetura antiga, representada por casarões e moinhos desativados da colonização italiana.

\section{Ponto 8: Formação Caturrita}

Afloramento situado no corte a leste da via que liga Novo Treviso a Faxinal do Soturno, em torno de 6 km de distância desta.

Neste ponto afloram arenitos intercalados por camada de pelito pertencente à Formação Caturrita. A estratificação cruzada acanalada sugere sedimentação em ambiente fluvial entrelaçado, cuja paleocorrente direciona-se para sudoeste.

\section{Ponto 9: Formação Botucatu}

A cerca de $5 \mathrm{~km}$ da sede municipal, a oeste da mesma estrada citada no ponto oito, expõe-se arenitos finos da Formação Botucatu.

As camadas apresentam inclinações distintas. Há faIha geológica pós-deposicional com deslocamento de blocos de arenitos.

No passado, o local era um extenso deserto formado por dunas eólicas, depositado no Período Cretáceo sobre a Formação Caturrita.

O arenito tem valor econômico importante, pois é utili- 
zado na construção civil. A visitação no local permite observar a origem deste material.

\section{Ponto 10: Formação Caturrita}

Mais a sul do ponto anterior, porém à margem leste da estrada, volta a aflorar arenito intercalado por camada de pelito da Formação Caturrita. Na base, expõe-se arenitos finos de cor esbranquiçada com concreções e acima desta aflora uma camada de pelito de cor roxa. No topo, deposita-se arenito médio com intraclastos na base.

A Formação Caturrita data do Período Triássico Superior, cuja litologia demonstra que no local havia areia e argila que foram levadas por enxurradas durante as inundações, revelando um ambiente fluvial. Devido as suas características litológicas é um afloramento potencialmente fossilífero.

\section{Ponto 11: Formação Caturrita}

À margem leste da estrada Novo Treviso-Faxinal do Soturno, expõe-se camadas de arenitos intercalados por pelitos, da Formação Caturrita.

Em épocas remotas, o local era um canal fluvial entrelaçado, sendo que em períodos de transbordamento de rápida duração, depositava-se sedimentos de granulação mais fina, denunciando regime de enxurradas, por isso, a predominância de pelitos.

Os pontos 9, 10 e 11 do roteiro estão próximos, por isso sugere-se caminhar de um ponto a outro, a fim de observar o contato das formações Botucatu e Caturrita.

Regressando à sede municipal, propõe-se uma pausa para apreciar a gastronomia da região e para um breve descanso.

\section{Ponto 12: Formação Caturrita}

Afloramento, localizado em Sítio Alto, propriedade privada.

$\mathrm{Na}$ base, expõe-se uma camada de arenito fino branco com cimento carbonático. Em seguida uma camada de siltito avermelhado, acima desta, uma camada de arenito fino com marcas de ondas e com concreções carbonáticas; novamente aparece uma camada de siltito avermelhado. No topo, há uma camada de arenito fino com concreções.

As características litológicas indicam uma possível planície de inundação ou um pequeno lago durante o Período Triássico Superior, data da Formação Caturrita. Afloramento potencialmente 118 Ciência \& Natura, Santa Maria, 23: 103 - 126, 2001. 
fossilífero, pois em épocas remotas, alguns animais que viviam às margens da planície de inundação ou do lago morriam e seus corpos poderiam ser levados pelas enxurradas para dentro do lago ou soterrados, imediatamente após sua morte. Em seguida, sofriam um processo de permineralização, em que a água infiltra-se nos espaços internos, como poros e cavidades dos ossos, e ali deposita-se elementos minerais carregados pela água. Dessa forma, os fragmentos de répteis são preservados até hoje.

\section{Ponto 13: Formação Caturrita}

Afloramento situado à margem leste da estrada Sítio Alto-Linha Guarda-Mor, próximo ao arroio dos Lanzos (Figura 2). O local é uma área escavada pela Prefeitura Municipal, na qual fez aflorar siltitos avermelhados com lentes descontínuas de arenitos, pertencentes à Formação Caturrita. A estrutura litológica indica ambiente fluvial durante o Período Triásico Superior.

Afloramento fossilífero, pois encontrou-se um fragmento de costela e uma vértebra de rincossauro, datando, aproximadamente 220 milhões de anos.

\section{Ponto 14: Formação Caturrita}

Este ponto está situado à margem leste da estrada RS 348 que liga Faxinal do Soturno a Dona Francisca, a 6 km da primeira.

Potencialmente fossilífero, indicado para estudos e pesquisas, além de visitações, em virtude da exposição de arenitos intercalados por siltitos e pelitos maciços da Formação Caturrita, do Período Triássico Superior.

\section{CONSIDERAÇÕES FINAIS}

O município de Faxinal do Soturno apresenta uma potencialidade para o desenvolvimento do turismo científico em Paleontologia, uma vez que a área possui fósseis datando o Período Triássico da Era Mesozóica.

Este inestimável patrimônio fossilífero, entretanto, é praticamente desconhecido pela maioria das pessoas, apesar do reconhecimento científico dos fósseis existentes na região (vide FACCINI, 1989).

Por essa razão, é importante o incentivo ao turismo científico, uma vez que a visitação no próprio local de ocorrência dos achados fossilifero desperta maior interesse por parte dos visitantes, 
pois estes estão em contato direto com a natureza, transferindo-se imaginavelmente a tempos remotos.

No entanto, para concretizar esta façanha, é necessário direcionar-se para a pesquisa no que se refere à identificação, interpretação e análise dos afloramentos encontrados no município, a fim de expor este conhecimento aos turistas.

É fundamental a conscientização da população no sentido de preservação do patrimônio fossilífero, bem como o interesse da administração municipal para que se possa estruturar um complexo turístico no município, assim como sua divulgação e toda a infra-estrutura adequada à recepção dos turistas.

A infra-estrutura local possui subsídios capazes de permitir a visitação. Entretanto, pode ser melhorada e valorizada, com o intuito de satisfazer os visitantes.

Assim, sugere-se as seguintes melhorias na infra-estrutura, equipamentos e serviços turísticos, em ordem de prioridade, cabendo aos órgãos públicos e/ou privados, bem como a comunidade local e regional a concretizá-los:

- Confecção de folhetos explicativos, estes devem fornecer explicações e descrições sobre as formações geológicas e os possíveis achados fossilíferos, um mapa detalhado com a identificação dos afloramentos indicados para visitação e como chegar ao local descrito. Devem salientar também informações relacionadas à infra-estrutura, equipamentos e serviços disponíveis no município. Além disso, os folhetos servem como referência ou lembrança da visita.

- Instalação de placas, sinalizando ao longo do caminho as localidades e os afloramentos. Estas placas devem conter breves informações sobre a formação geológica, a altitude, a distância em quilômetros da sede municipal e a potencialidade fossilífera do afloramento. As placas devem ser de material resistente às intempéries, para não causar danos nas informações.

- Implantação de postos de atendimento ao turista, possuindo sanitários, lojas de conveniências, bancas com a venda de produtos caseiros e agrícolas da região, comercialização de cartões postais, mapas do município e roteiro turístico, juntamente com folhetos explicativos.

- Promover o turismo científico em paleontologia, através dos meios de comunicação, das agências de turismo e de "stands" de exposição, em feiras regionais. A prefeitura municipal poderá convidar e receber pesquisadores e estudiosos, com o intuito de 
aprofundar os estudos sobre geologia e paleontologia. Operadores turísticos, escritores e fotógrafos publicarão e divulgarão em jornais e revistas os estudos realizados.

- Construção de alojamentos, como albergues, cabanas e pousadas. A hospedagem pode ser feita em prédios restaurados, cuja arquitetura antiga revela a colonização italiana na região.

- Instalação de restaurantes, nas localidades próximas aos afloramentos, dispondo da culinária típica da região.

- Condições adequadas de fluxo, como manutenção das principais rodovias e conservação e posterior pavimentação das vias secundárias.

- Construção de estacionamentos, denominados "refúgios", para possíveis paradas de veículos nas estradas próximas aos afloramentos.

- Criar um centro de informação a turistas, localizado na sede municipal em prédio especial. Neste centro serão expostas fotografias, painéis com texto explicativo, mapas, folders e folhetos explicativos, a fim de satisfazer os interesses e dúvidas sobre a área e os afloramentos, assim como livros e guias turísticos para venda.

- Estabelecimento de um centro de educação, situado em prédio específico ou em espaços reservados juntamente com o centro de informação. Trata-se de salas que permitam dar aulas, palestras ou sessões de discussão, com equipamentos audiovisuais para mostrar filmes ou produções em vídeo.

- Transporte coletivo, capaz de conduzir os visitantes da sede municipal aos afloramentos propostos, com horários regulares a preços acessíveis.

- Melhorias na infra-estrutura básica, em especial nas localidades próximas aos afloramentos sugeridos para visitação. Fazse necessário melhorias no que se refere ao sistema de iluminação pública, calçamento, extensão da rede de telefone, abastecimento de água, sistema de esgoto, sistema de coleta de lixo e a instalação de um posto de saúde, posto policial e um posto da Empresa Brasileira de Correios e Telégrafos.

- Criação de cursos profissionalizantes ou adequação dos já existentes, especialmente de intérprete-guia, com o intuito de capacitá-los no que se refere aos conhecimentos e como relacionarse com os visitantes. O centro de informação deve dispor de intérprete-guia para acompanhar grupos de visitantes, principalmente visitas escolares que envolvem grupos de crianças, até os afloramentos indicados. O guia transmite seus conhecimentos e informações, bem como a necessidade de preservação do ambiente, através de uma 
conversa informal com os visitantes.

- Determinar leis de proteção ao meio ambiente. Cabe aos órgãos públicos e à comunidade a conscientização da importância da preservação e manutenção dos afloramentos naturais e artificiais existentes no município, assim como os equipamentos dirigidos aos visitantes. Para isto, faz-se necessário a implantação de leis de proteção ao meio ambiente, em especial nos locais notadamente fossiliferos, a fim de evitar a retirada de material para aterro ou construção de açudes e estradas.

Estes empreendimentos beneficiarão tanto os turistas e pesquisadores, como a população local, pois além de atender as necessidades básicas dos visitantes, geram recursos econômicos para o município e para a população na forma de arrecadação de impostos e taxas, bem como a geração de empregos formais e informais. A boa impressão do município faz com que os visitantes voltem, no futuro, com mais pessoas. É a maneira mais informal de divulgação do turismo. 


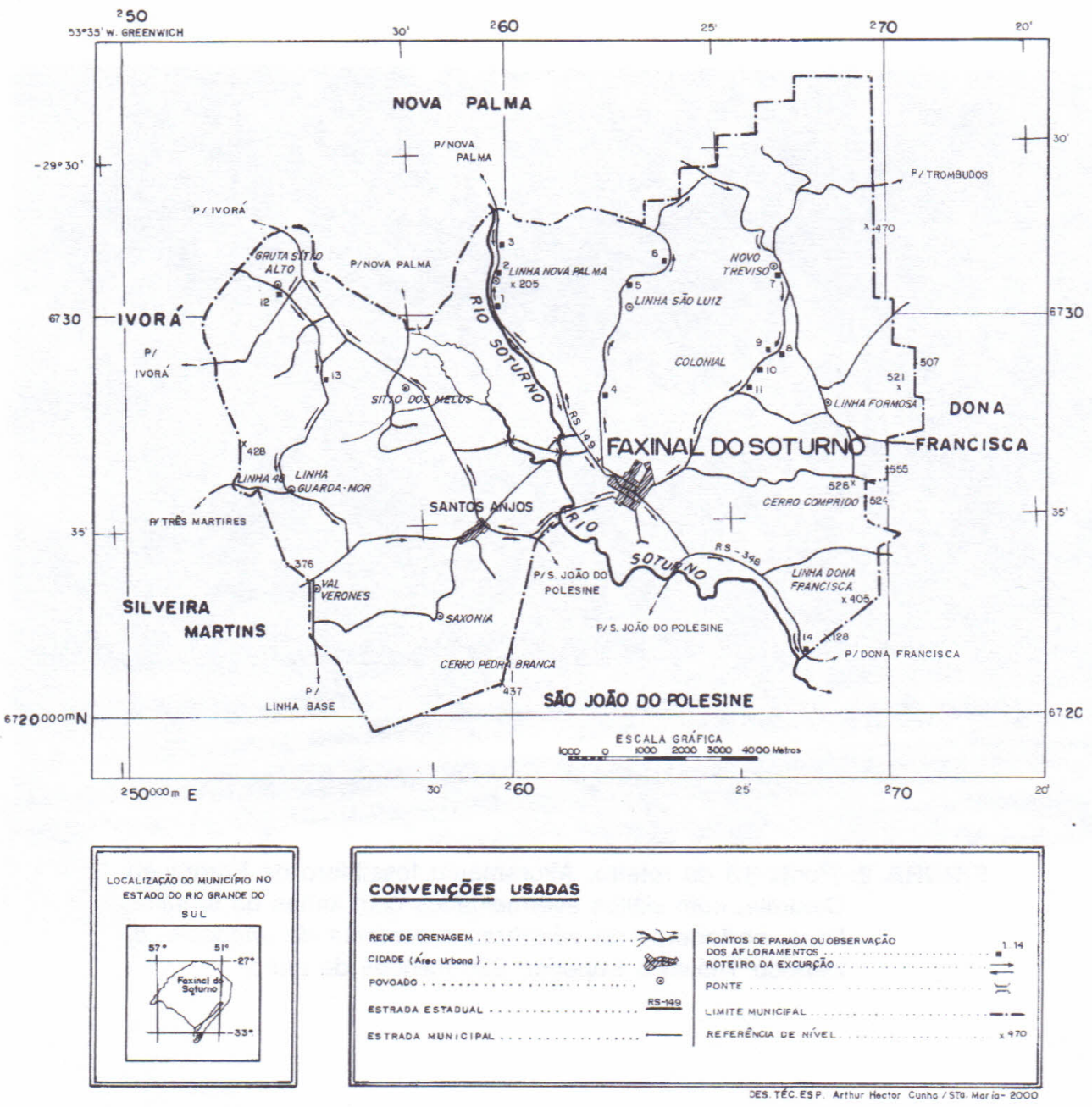

FIGURA 1: Proposta de roteiro turístico para o município de Faxinal do Soturno - RS 


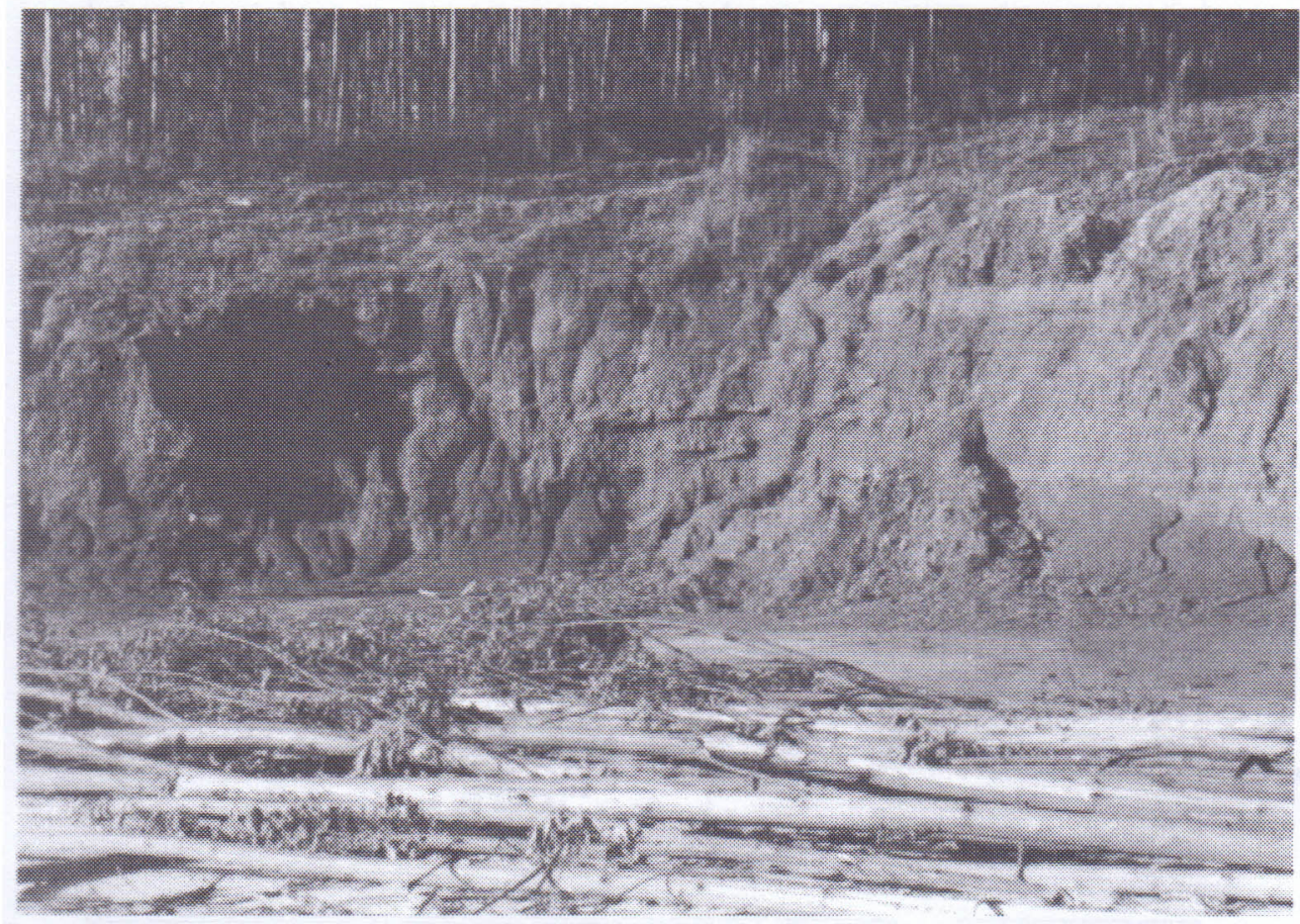

FIGURA 2: Ponto 13 do roteiro. Afloramento fossilífero da Formação Caturrita, com siltitos avermelhados com lentes de arenitos finos, portadores de vértebras e costelas de rincossauro. Período Triássico Superior, 220 milhões de anos. 


\section{BIBLIOGRAFIA}

BARATTO, J. \& BARROS SARTORI, G. M. da. Organização do espaço geográfico dos municípios de Faxinal do Soturno e São João do Polêsine - RS. Revista Geografia: Ensino e Pesquisa. Santa Maria: Universidade Federal de Santa Maria, (6-7): 204228, set. 1994.

BENI, M. C. Análise estrutural do turismo. 2. ed. São Paulo: Editora SENAC. São Paulo, 1998. 427 p.

CAVACO, C. Turismo rural e desenvolvimento local. In: RODRIGUES, A. A. B. (org.). Turismo e Geografia: reflexões teóricas e enfoques regionais. São Paulo: Hucitec, 1996. p. 94-121.

CESCA, O. Faxinal do Soturno: sua história e sua gente. Santa Maria: Rainha, 1975. 188 p.

CORADINI, M. As possibilidades turísticas de Faxinal do Soturno - RS. Santa Maria: Universidade Federal de Santa Maria, CCNE, Departamento de Geociências, 1997. (Trabalho de Graduação A).

CORIOLANO, L. N. M. T. Turismo e degradação ambiental no litoral do Ceará. In: LEMOS, A. (org.), Turismo: impactos sócioambientais. São Paulo: Hucitec, 1996. p. 93-103.

FACCINI, U. F. O Permo-Triássico do Rio Grande do Sul. Uma análise sob o ponto de vista das seqüências deposicionais. Porto Alegre: UFRGS, Curso de Pós-Graduação em Geociências, 1989.133p. (Dissertação de Mestrado)

FUNDAÇÃO DE ECONOMIA E ESTATÍSTICA. Anuário Estatístico do Rio Grande do Sul. Porto Alegre: FEE, 1995.

MAPA GEOLÓGICO DO ESTADO DO RIO GRANDE DO SUL. EScala 1: 1000000. Mapa n. ${ }^{\circ}$ 8. Outubro, 1974. Instituto de Geociências, Universidade Federal do Rio Grande do Sul, Porto Alegre, Brasil.

MCINTYRE, G. Desenvolvimento de turismo sustentável: manual para organizadores locais. Organização Mundial de Turismo. Publicação de Turismo e Ambiente, 1994. 217 p.

PAGANI, M. I.; SCHIAVETTI, A.; MORAES, M. E. B. \& TOREZAN, F. H. As trilhas interpretativas da natureza e o ecoturismo. In: LEMOS, A. (Org.). Turismo: impactos sócio ambientais. São Paulo: Hucitec, 1996. p. 151-163.

REJOWSKI, M. Turismo e pesquisa científica: pensamento internacional x situação brasileira. Campinas/São Paulo: Papirus, 1996. $167 \mathrm{p}$. 
RODRIGUES, A. A. B. (Org.). Turismo e geografia: reflexões teóricas e enfoques regionais. São Paulo: Hucitec, 1996. 273 p. SECRETARIA DE AGRICULTURA E ABASTECIMENTO (SAA). EMBRAPA.Centro Nacional de Pesquisa do Trigo. Macrozoneamento Agroecológico e Econômico do Estado do Rio Grande do Sul. Porto Alegre: SAA/CNPT, v. I, 1994. $307 \mathrm{p}$.

SERVIÇO NACIONAL DE APRENDIZAGEM COMERCIAL - SENAC. Cursos STCAS. Noções de turismo. Rio Grande do Sul. 1998 a. $66 \mathrm{p}$.

SERVIÇO NACIONAL DE APRENDIZAGEM COMERCIAL - SENAC. Cursos STCAS Geografia aplicada ao turismo. Rio Grande do Sul. 1998b. 26p.

SERVIÇO NACIONAL DE APRENDIZAGEM COMERCIAL - SENAC. Cursos STCAS. Turismo e ecoturismo: teoria e prática. Rio Grande do Sul. 1998c. 62 p.

SERVIÇO NACIONAL DE APRENDIZAGEM COMERCIAL - SENAC. Cursos STCAS Ecoturismo: gestão de projetos. Rio Grande do Sul. 1998d. $37 \mathrm{p}$.

SILVA, L. L. da. Ecologia: manejo de áreas silvestres. Santa Maria: MMA, FNMA, FATEC, 1996. 352 p.

ELIANE FERREIRA DOS SANTOS ÁTILA AUGUSTO STOCK DA ROSA Departamento de Geociências CCNE/UFSM Santa Maria, RS 